\title{
Minimal hepatic encephalopathy
}

\author{
Laura M Stinton MD MSc FRCPC, Saumya Jayakumar MD FRCPC
}

LM Stinton, S Jayakumar. Minimal hepatic encephalopathy. Can J Gastroenterol 2013;27(10):572-574.

Minimal hepatic encephalopathy (MHE) is the earliest form of hepatic encephalopathy and can affect up to $80 \%$ of cirrhotic patients. By definition, it has no obvious clinical manifestation and is characterized by neurocognitive impairment in attention, vigilance and integrative function. Although often not considered to be clinically relevant and, therefore, not diagnosed or treated, MHE has been shown to affect daily functioning, quality of life, driving and overall mortality. The diagnosis of MHE has traditionally been achieved through neuropsychological examination, psychometric tests or the newer critical flicker frequency test. A new smartphone application (EncephalApp Stroop Test) may serve to function as a screening tool for patients requiring further testing. In addition to physician reporting and driving restrictions, medical treatment for MHE includes nonabsorbable disaccharides (eg, lactulose), probiotics or rifaximin. Liver transplantation may not result in reversal of the cognitive deficits associated with MHE.

Key Words: Hepatic encephalopathy; Minimal hepatic encephalopathy; Neurocognitive testing; Quality of life

\section{Une encéphalopathie hépatique minimale}

L'encéphalopathie hépatique minimale (EHM) est la forme la plus précoce d'encéphalopathie hépatique. Elle peut toucher jusqu'à $80 \%$ des patients cirrhotiques. Par définition, elle n'a pas de manifestations cliniques évidentes et se caractérise par une atteinte neurocognitive de l'attention, de la vigilance et de la fonction intégrative. Souvent, elle n'est pas considérée comme pertinente sur le plan clinique et n'est donc pas diagnostiquée ou traitée, mais elle nuit au fonctionnement quotidien, à la qualité de vie, à la conduite automobile et à la mortalité globale. D'ordinaire, pour diagnostiquer l'EHM, on procède à un examen neuropsychologique, à des tests psychométriques ou à la mesure plus récente de la fréquence critique de fusion. Une nouvelle application pour téléphone intelligent (EncephalApp Stroop Test) peut être utilisée comme outil de dépistage auprès des patients qui ont besoin de subir des examens plus approfondis. En plus de la déclaration par le médecin et des restrictions relatives à la conduite automobile, le traitement médical de l'EHM inclut la prise de disaccharides non absorbables (p. ex., lactulose), de probiotiques ou de rifaximine. La transplantation hépatique ne renverse pas nécessairement les déficits cognitifs associés à l'EHM.

\begin{abstract}
T $\mathrm{t}$ is well known that $30 \%$ to $45 \%$ of patients with cirrhosis (1) develop a spectrum of potentially reversible neurocognitive deficits, termed 'hepatic encephalopathy' (HE). These deficits can range from subtle, including fatigue and day-night reversal, to severe including focal neurological deficits and coma (2). The development of overt $\mathrm{HE}$ is associated with poor outcomes, with reportedly decreased survival rates after even the first episode of HE (3).

Minimal HE (MHE), previously known as subclinical or latent encephalopathy, represents the earliest stage of the spectrum and, by definition, is not clinically apparent. MHE occurs in up to $80 \%$ of patients with cirrhosis and manifests as abnormalities in central nervous system function, with significant impairments in attention, psychomotor speed, visuospatial perception, response inhibition and delayed information processing $(4,5)$. MHE can also occur in patients with noncirrhotic liver disease such as portal vein thrombosis or portosystemic shunts (6). Given its covert nature, the diagnosis of MHE is made through neuropsychiatric testing.
\end{abstract}

\section{BURDEN OF MHE}

Because it is not obviously apparent, MHE is often believed to lack a significant impact on patient quality of life ( $\mathrm{QoL})$ or ability to function and, thus, frequently remains undiagnosed. However, studies have shown that it is the leading cause of cognitive dysfunction in cirrhotic patients (7), with marked impairment in both QoL and job performance $(8,9)$. Furthermore, MHE is associated with an increased risk of developing overt $\mathrm{HE}$ and overall mortality (10). Interestingly, although Child-Pugh scores are higher in patients with MHE compared with those without, there is no direct association between the two (11).

Groeneweg et al (9) examined health-related QoL (HRQoL) in patients with cirrhosis undergoing testing for MHE using a 'Sickness Impact Profile'. This questionnaire evaluates patient perception of social interaction, alertness, emotional behaviour, mobility, sleep/rest, home management, recreation and past times. Patients with MHE reported lower scores in all areas compared with patients without MHE, with the areas of highest impact being alertness, home management, work, recreational activities and sleep. Similar findings were reported in a study by Schomerus and Hamster (8).

Although initially examined in the mid-1990s $(12,13)$, studies on MHE and driving have re-emerged in the past decade with concerning results. A study from 2004 found that patients with MHE had overall lower total driving scores (defined as skills in car handling, adaptation to traffic situations, cautiousness and manoeuvring) on a standardized on-road test compared with non-MHE controls (14). The professional driving instructor, who was blinded to the patient's diagnosis, had to intervene more frequently in the MHE group to avoid potential accidents. Other studies have shown that cirrhotic patients with MHE have impaired navigation skills during driving simulation (13), and also self-report a significantly higher rate of violations and motor vehicle accidents than controls $(15,16)$. Other studies examining problems with driving in patients with MHE demonstrated that patients also experienced difficulty with decision making, planning (navigation) and ability to perform tasks when their attention was divided (17). Given that the cognitive processes required for driving - attention, ability to respond quickly, visuomotor coordination and short-term recall - are the same processes adversely affected by MHE, it is no surprise that patients with MHE are at higher risk for motor vehicle collisions. A study by Bajaj et al (18), which examined the cost effectiveness of diagnosis and treatment of MHE as a means to reduce societal costs related to motor vehicle accidents, found that diagnosis and treatment with available medications would save from $\$ 1.7$ million to $\$ 3.6$ million over a five-year period in the United States.

\section{DIAGNOSIS}

The diagnosis of MHE is often overlooked because the major deficits are in the areas of overall performance and psychomotor activities, with verbal functioning usually preserved. A survey of members of the

Division of Gastroenterology, Department of Medicine, Faculty of Medicine, University of Calgary, Calgary, Alberta

Correspondence: Dr Laura M Stinton, Division of Gastroenterology, Faculty of Medicine, University of Calgary, Teaching, Research and Wellness

Building, Room 6D58, 3280 Hospital Drive Northwest, Calgary, Alberta T2N 4Z6. Telephone 403-592-5010, fax 403-592-5080,

e-mail laura.stinton@ucalgary.ca

Received for publication May 28, 2013. Accepted June 23, 2013 
American Association for the Study of the Liver found that although $84 \%$ believed that MHE was a clinically significant issue, almost $40 \%$ of respondents had never tested for MHE (19). Unfortunately, there is no general consensus on whom to test for MHE. Although some groups recommend screening of all cirrhotic patients, this can be impractical given the substantial number and cost. However, testing should be completed in patients at risk for MHE (cirrhosis or portosystemic shunts) who are in jeopardy of accidents and complain of decreased cognition or a decline in work performance (20) (Figure 1).

Before initiating testing for MHE, we recommend that obvious neurological causes of cognitive impairment (ischemia, inherited or metabolic causes of dementia) and overt HE be ruled out. This can be best accomplished with a combination of a neurological examination and a mini-mental status examination. If these are negative, one can proceed to testing of MHE (Figure 1).

Referral to a neuropsychologist for thorough expert assessment is expensive and time consuming, and a standard battery of psychometric tests dedicated to making the diagnosis has not been established. Some short neuropsychological tests, including the trail-making test, symbol digit modalities test and block design test have been used in the diagnosis of MHE, although none were specifically designed for this purpose. The currently recommended method to diagnosis MHE is based on a combination of psychometric test procedures, the Psychometric Hepatic Encephalopathy Score. This battery of tests was specifically developed for MHE and has been validated in this population. It includes five paper-and-pencil tests including number connection tests $\mathrm{A}$ and $\mathrm{B}$, the digit symbol test, the serial dotting test and the linedrawing test $(21,22)$. Another increasingly used test is the critical flicker frequency test. This has been shown to predict MHE with the advantage of not being affected by age or educational level (23).

However, none of these tests are readily available to the general hepatologist in the clinic setting. A recent study by Bajaj et al (24) examined the role of a smartphone application (EncephalApp Stroop Test) in the setting of screening patients with cirrhosis for MHE (www. encephalapp.com [accessed April 30, 2013]). The investigators found that patients with MHE performed more poorly compared with their counterparts without cirrhosis and normal controls (total time $365 \mathrm{~s}$ versus 271 s versus $217 \mathrm{~s}$, respectively) (24). This application is freely available to individuals with a smartphone (although only through the Apple Store, Apple Inc, USA), is not prohibitively time consuming and is a possible tool to screen patients at risk for MHE. A total time $>274.9 \mathrm{~s}$ is believed to be suggestive of MHE (area under the curve of 0.89 in all patients and 0.84 in patients without previous overt HE) (24). However, further testing to establish and validate cut-offs for both normal and abnormal parameters is still being undertaken, and will be needed to help rule out MHE (personal communication, Dr J Bajaj, Virginia Commonwealth University, Virginia, USA).

\section{TREATMENT}

Treatment of MHE should initially be directed toward altering lifestyle habits including avoidance of situations that may lead to accidents and potential driving restrictions. When a diagnosis of MHE is suspected or confirmed, the issue of driving and the implications that this has on the patient must be discussed. The Canadian Medical Association's Determining Medical Fitness to Operate Motor Vehicles was last published in 2006 (7th edition) (25). It states that "Patients with symptomatic hepatic encephalopathy should not be allowed to drive any type of motor vehicle". Although each provincial jurisdiction differs, it is typically mandatory for physicians to report potentially unfit drivers to the motor vehicle licensing authority and that this should be discussed and documented in the patient's medical chart.

Unlike overt HE, only a few randomized control trials for the treatment of MHE exist. Medical treatment of MHE is currently directed toward reduction of gut-derived ammonia. The majority of current data is for lactulose and lactitol, both of which are nonabsorbable disaccharides. Lactulose has been shown to improve cognitive function, HRQoL and psychometric tests in patients with MHE (26,27). Bajaj et al (18)

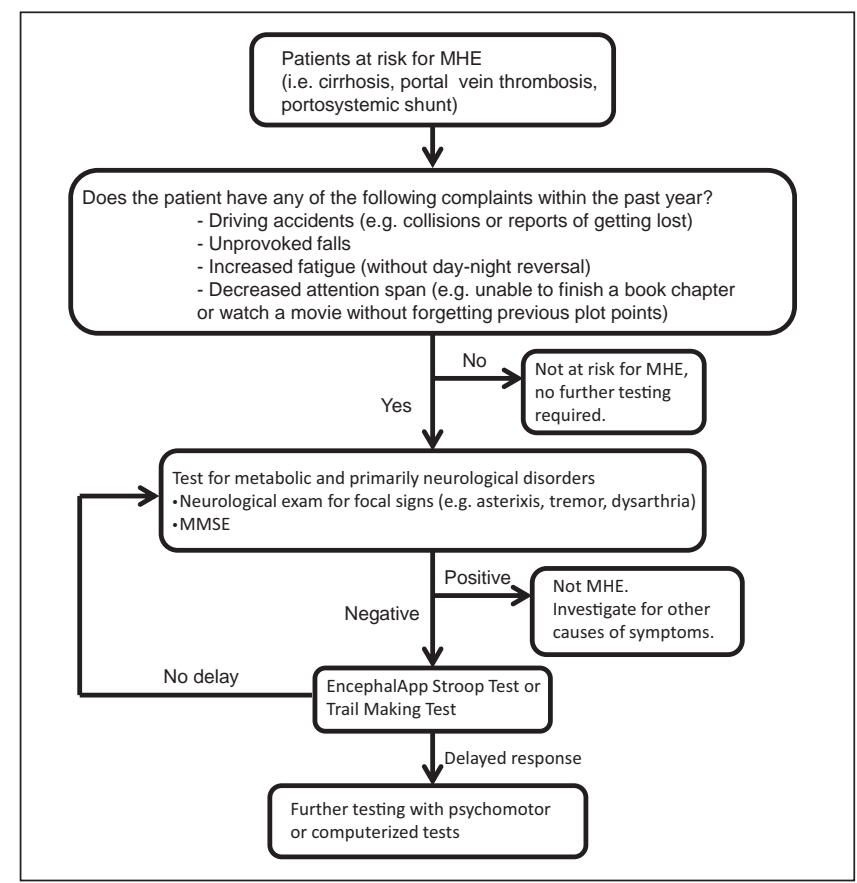

Figure 1) Screening patients for minimal hepatic encephalopathy (MHE). MMSE Mini-mental status examination

found that treating patients with lactulose decreased possible motor vehicle accidents, as assessed during a five-year follow-up period and repeat MHE testing. Other treatment options include modulation of gut flora through the use of prebiotics and probiotics $(27,28)$; a recent metaanalysis (29) showed a significant improvement in MHE as measured by psychometric and neurophysiological testing.

Rifaximin, a nonabsorbable gut-specific antibiotic, is well known to improve symptoms of overt HE (30). Although there are only a few trials examining the efficacy of rifaximin in MHE, the current evidence suggests that rifaximin use improves neurophysiological and psychometric tests and HRQoL (31), as well as improvement in driving simulator performance (32). Unfortunately, in Canada, rifaximin can only be obtained through special access.

In patients undergoing liver transplantation for cirrhosis, the deficits related to MHE may improve (33); however, a significant number of patients demonstrate only marginal or even no improvement in their visuomotor or visuoconstructive functioning (34). This led to the hypothesis that there may be two types of MHE: delirium-like MHE, which is reversible with transplant; and 'dementia-like MHE', which is not reversible with transplant (35).

\section{SUMMARY}

MHE constitutes a significant medical problem in a common patient population. Unfortunately, it is often underdiagnosed, likely related to the notion that testing is time consuming requiring highly specialized personnel. Additionally, the term 'MHE' may create the impression that this condition has limited impact on patient's well being; however, it has been shown that MHE has clinical implications on the patient as well as public safety concerns.

Diagnosing and treating MHE is difficult owing to the subclinical nature of the disease. Physicians in Canada have an obligation to investigate and manage this condition appropriately and should have a low index of suspicion for doing so. We recommend screening with either a trail-making test or the EncephalApp Stroop Test in all patients with cirrhosis or portsystemic shunts and neurocognitive symptoms.

In patients who are found to have MHE, treatment with lactulose has the most supportive evidence for improvement of both psychometric tests and driving simulation, although rifaximin and gut modulation through pre- and probiotics have also shown benefit. 
ACKNOWLEDGEMENTS: The authors thank Dr J Bajaj for his advice regarding the use of the EncephalApp and the Stroop test as a screening tool for minimal hepatic encephalopathy.

\section{REFERENCES}

1. Poordad FF. The burden of hepatic encephalopathy. Aliment Pharmacol Ther 2007;25(Suppl 1):3-9.

2. Ferenci P, Lockwood A, Mullen K, Tarter R, Weissenborn K, Blei AT. Hepatic encephalopathy - definition, nomenclature, diagnosis, and quantification: Final report of the working party at the 11th World Congresses of Gastroenterology, Vienna, 1998. Hepatology 2002;35:716-21.

3. Bustamante J, Rimola A, Ventura PJ, et al. Prognostic significance of hepatic encephalopathy in patients with cirrhosis. J Hepatol 1999;30:890-5.

4. Amodio P, Montagnese S, Gatta A, Morgan MY. Characteristics of minimal hepatic encephalopathy. Metab Brain Dis 2004;19:253-67.

5. Das A, Dhiman RK, Saraswat VA, Verma M, Naik SR. Prevalence and natural history of subclinical hepatic encephalopathy in cirrhosis. J Gastroenterol Hepatol 2001;16:531-5.

6. Minguez B, Garcia-Pagan JC, Bosch J, et al. Noncirrhotic portal vein thrombosis exhibits neuropsychological and MR changes consistent with minimal hepatic encephalopathy. Hepatology 2006;43:707-14.

7. Bajaj JS, Wade JB, Sanyal AJ. Spectrum of neurocognitive impairment in cirrhosis: Implications for the assessment of hepatic encephalopathy. Hepatology 2009;50:2014-21.

8. Schomerus H, Hamster W. Quality of life in cirrhotics with minimal hepatic encephalopathy. Metab Brain Dis 2001;16:37-41.

9. Groeneweg M, Quero JC, De Bruijn I, et al. Subclinical hepatic encephalopathy impairs daily functioning. Hepatology 1998;28:45-9.

10. Dhiman RK, Kurmi R, Thumburu KK, et al. Diagnosis and prognostic significance of minimal hepatic encephalopathy in patients with cirrhosis of liver. Dig Dis Sci 2010;55:2381-90.

11. Sharma P, Sharma BC. Predictors of minimal hepatic encephalopathy in patients with cirrhosis. Saudi J Gastroenterol 2010;16:181-7.

12. Srivastava A, Mehta R, Rothke SP, Rademaker AW, Blei AT. Fitness to drive in patients with cirrhosis and portal-systemic shunting: A pilot study evaluating driving performance. J Hepatol 1994;21:1023-8.

13. Watanabe A, Tuchida T, Yata Y, Kuwabara Y. Evaluation of neuropsychological function in patients with liver cirrhosis with special reference to their driving ability. Metab Brain Dis 1995;10:239-48.

14. Wein C, Koch H, Popp B, Oehler G, Schauder P. Minimal hepatic encephalopathy impairs fitness to drive. Hepatology 2004;39:739-45.

15. Bajaj JS, Hafeezullah M, Hoffmann RG, Saeian K. Minimal hepatic encephalopathy: A vehicle for accidents and traffic violations. Am J Gastroenterol 2007;102:1903-9.

16. Bajaj JS, Saeian K, Schubert CM, et al. Minimal hepatic encephalopathy is associated with motor vehicle crashes: The reality beyond the driving test. Hepatology 2009;50:1175-83.

17. Bajaj JS, Hafeezullah M, Hoffmann RG, et al. Navigation skill impairment: Another dimension of the driving difficulties in minimal hepatic encephalopathy. Hepatology 2008;47:596-604.

18. Bajaj JS, Pinkerton SD, Sanyal AJ, Heuman DM. Diagnosis and treatment of minimal hepatic encephalopathy to prevent motor vehicle accidents: A cost-effectiveness analysis. Hepatology 2012;55:1164-71.
19. Bajaj JS, Etemadian A, Hafeezullah M, Saeian K. Testing for minimal hepatic encephalopathy in the United States: An AASLD survey. Hepatology 2007;45:833-4.

20. Ortiz M, Jacas C, Cordoba J. Minimal hepatic encephalopathy: Diagnosis, clinical significance and recommendations. J Hepatol 2005;42 Suppl:S45-53.

21. Randolph C, Hilsabeck R, Kato A, et al. Neuropsychological assessment of hepatic encephalopathy: ISHEN practice guidelines. Liver Int 2009;29:629-35.

22. Duarte-Rojo A, Estradas J, Hernandez-Ramos R, Ponce-de-Leon S, Cordoba J, Torre A. Validation of the psychometric hepatic encephalopathy score (PHES) for identifying patients with minimal hepatic encephalopathy. Dig Dis Sci 2011;56:3014-23.

23. Romero-Gomez M. Critical flicker frequency: It is time to break down barriers surrounding minimal hepatic encephalopathy. J Hepatol 2007;47:10-1.

24. Bajaj JS, Thacker LR, Heuman DM, et al. The Stroop smartphone application is a short and valid method to screen for minimal hepatic encephalopathy. Hepatology 2013; February 6 (E-pub ahead of print).

25. Canadian Medical Association. Determining Medical Fitness to Operate Motor Vehicles: CMA Driver's Guide, 7th edn. Ottawa: Canadian Medical Association, 2006.

26. Prasad S, Dhiman RK, Duseja A, Chawla YK, Sharma A, Agarwal R. Lactulose improves cognitive functions and health-related quality of life in patients with cirrhosis who have minimal hepatic encephalopathy. Hepatology 2007;45:549-59.

27. Sharma P, Sharma BC, Puri V, Sarin SK. An open-label randomized controlled trial of lactulose and probiotics in the treatment of minimal hepatic encephalopathy. Eur J Gastroenterol Hepatol 2008;20:506-11.

28. Liu Q, Duan ZP, Ha DK, Bengmark S, Kurtovic J, Riordan SM. Synbiotic modulation of gut flora: Effect on minimal hepatic encephalopathy in patients with cirrhosis. Hepatology 2004;39:1441-9.

29. Shukla S, Shukla A, Mehboob S, Guha S. Meta-analysis: The effects of gut flora modulation using prebiotics, probiotics and synbiotics on minimal hepatic encephalopathy. Aliment Pharmacol Ther 2011;33:662-71.

30. Bass NM, Mullen KD, Sanyal A, et al. Rifaximin treatment in hepatic encephalopathy. N Engl J Med 2010;362:1071-81.

31. Sidhu SS, Goyal O, Mishra BP, Sood A, Chhina RS, Soni RK. Rifaximin improves psychometric performance and health-related quality of life in patients with minimal hepatic encephalopathy (the RIME Trial). Am J Gastroenterol 2011;106:307-16.

32. Bajaj JS, Heuman DM, Wade JB, et al. Rifaximin improves driving simulator performance in a randomized trial of patients with minimal hepatic encephalopathy. Gastroenterology 2011;140:478-87:e1.

33. Mattarozzi K, Stracciari A, Vignatelli L, D’Alessandro R, Morelli MC, Guarino M. Minimal hepatic encephalopathy: Longitudinal effects of liver transplantation. Arch Neurol 2004;61:242-7.

34. Mechtcheriakov S, Graziadei IW, Mattedi M, et al. Incomplete improvement of visuo-motor deficits in patients with minimal hepatic encephalopathy after liver transplantation. Liver Transpl 2004;10:77-83.

35. Rose C, Jalan R. Is minimal hepatic encephalopathy completely reversible following liver transplantation? Liver Transpl 2004;10:84-7. 


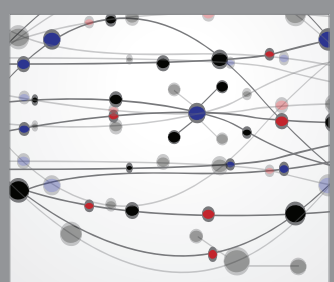

The Scientific World Journal
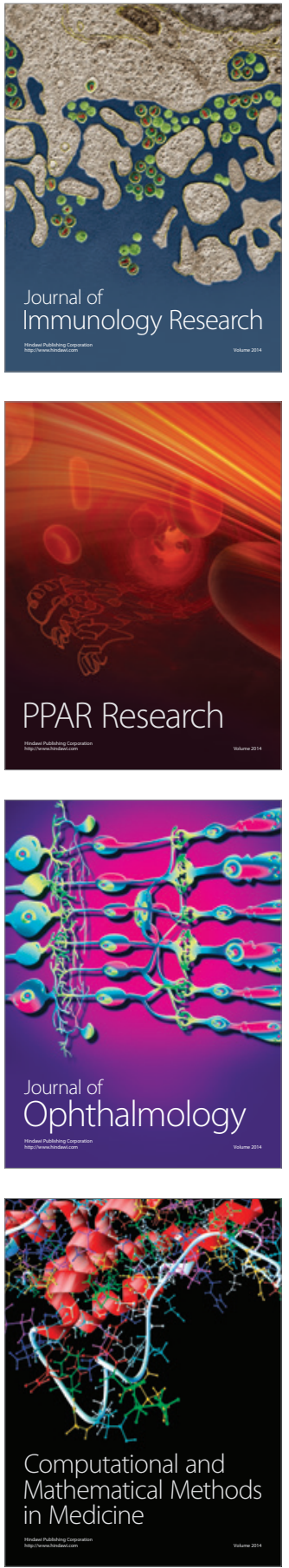

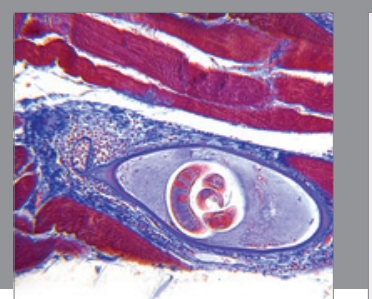

Gastroenterology Research and Practice

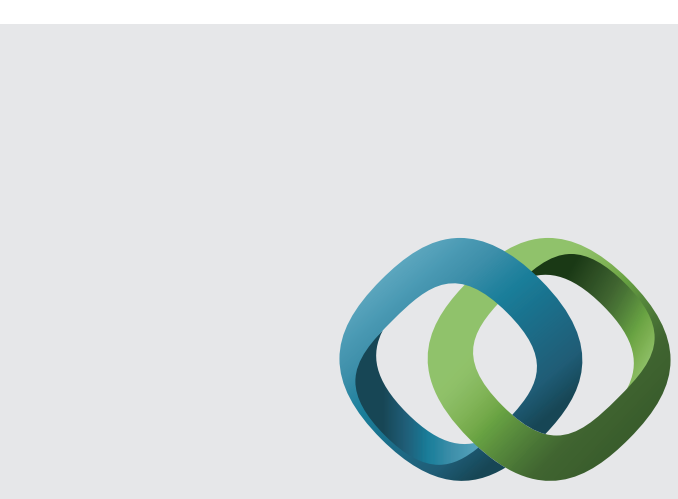

\section{Hindawi}

Submit your manuscripts at

http://www.hindawi.com
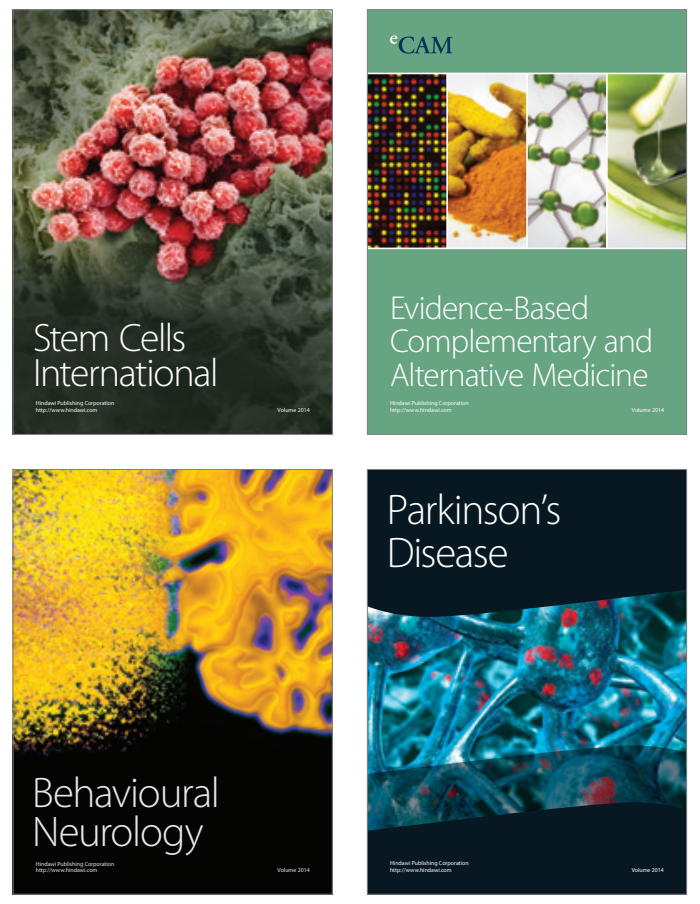
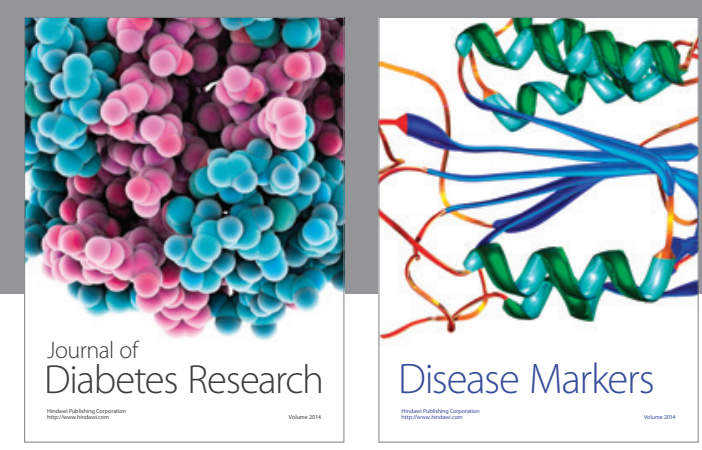

Disease Markers
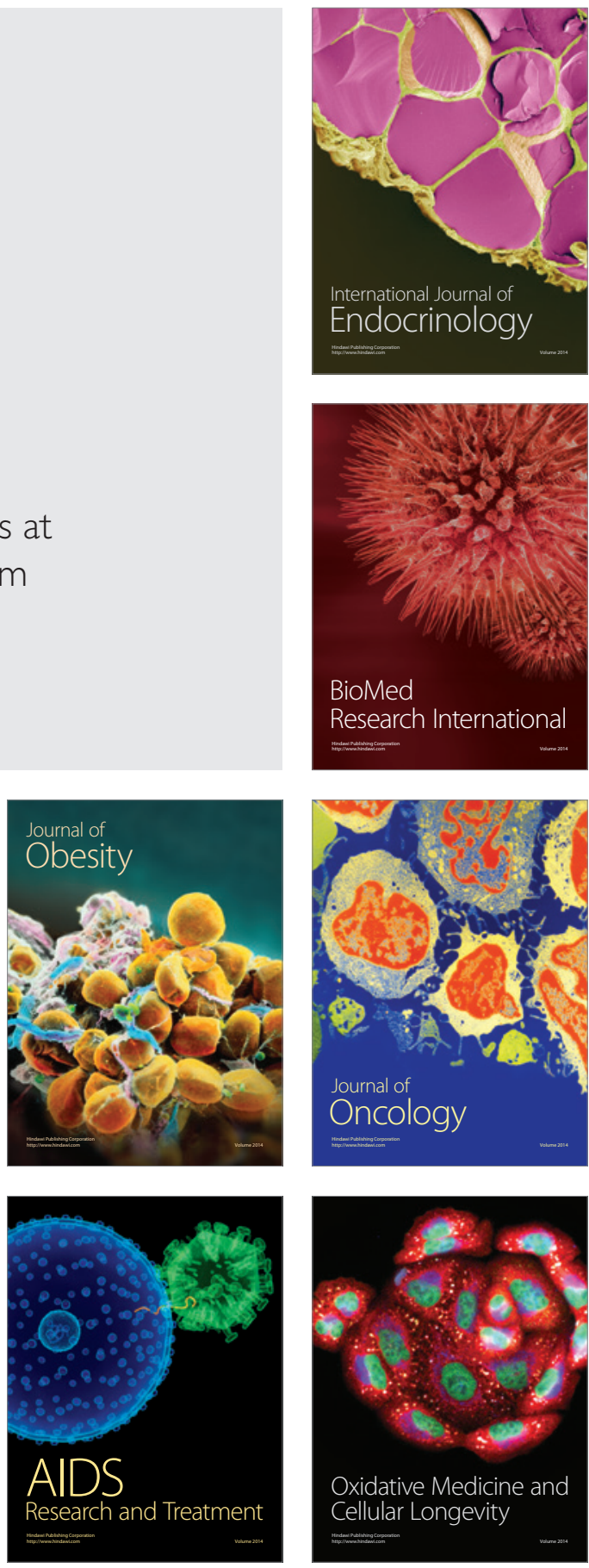